\title{
La cara ètica del «bon» mestre: ethos docent, identitat professional i lideratge moral
}

\author{
Maria Rosa Buxarrais * \\ Amèlia Tey ${ }^{* *}$
}

\section{Resum}

Respondre a la pregunta de com es fa un bon mestre és força complex, perquè cadascú atribueix significats diferents al terme «bon» i perquè hi intervenen elements variats i molt diversos. No obstant això, a partir de l'acord que sembla haver que tot allò que constitueix el «bon» mestre forma part de l'«ethos docent», en l'article es desenvolupa el que configura el rol de mestre des de la vessant ètica, element component imprescindible, vinculant-lo amb els conceptes d'identitat professional i lideratge moral, en els que les actituds en les relacions hi juguen un paper essencial. L'article, des de la vessant teòrica, corrobora i complementa els resultats de les dades d'una recerca amb una mostra de mestres en exercici, considerats «bons» pels seus companys i, a partir de la qual, van emergir quines eren les característiques del que consideraven un «bon mestre».

\section{Paraules clau}

Ethos docent, identitat professional, lideratge moral, formació de professorat, educació moral, mestre, ètica professional.

Recepció original: 15 de juliol de 2019

Acceptació: 31 d'octubre de 2019

Publicació: 20 de gener de 2020

\section{Introducció ${ }^{1}$}

La paraula «bon» té tant força moral com epistemològica. Preguntar què és «bon» mestre en el sentit moral equival a preguntar quines accions docents poden justificar-se basant-se en principis morals i són capaços de provocar accions de prin-

(*) Catedràtica d'Universitat del Departament de Teoria i Història de l'Educació, Facultat d'Educació, Universitat de Barcelona. Investigadora Principal del Grup de Recerca en Educació Moral (GREM) de la UB. Directora de l'Observatori de Civisme i Valors de la Generalitat de Catalunya. Responsable de la Secció de Recerca de I'Institut de Desenvolupament Professional (IDP-ICE). Els seus temes d'estudi són: I'educació moral, la formació dels/les mestres, la recerca en docència universitària, l'ètica cívica, entre d'altres. Més informació: mariarosabuxarrais.com. Adreça electrònica: mrbuxarrais@ub.edu

(**) Professora de la Facultat d'Educació a la Universitat de Barcelona i coordinadora del Màster en Psicopedagogia de la mateixa universitat. Membre del Grup de Recerca en Educació Moral (GREM) de la UB. Doctora en Pedagogia i llicenciada en Psicologia per la Universitat de Barcelona. Estudia els aspectes pedagògics i psicològics relacionats amb els valors, les emocions i els sentiments, i l'aprenentatge. Adreça electrònica: atey@ub.edu

(1) Aquest article és resultat parcial del projecte de recerca «El caràcter dels bons mestres: anàlisi dels seus trets i promoció en la formació inicial a partir d'un programa formatiu centrat en la reflexió ètica i la pràctica real als centres educatius» (IP Francisco Esteban), seleccionat en la convocatòria, ARMIF 2015 (codi 2015 ARMIF 00013), subvencionada per l'Agència Catalana d'Universitats i Recerca (AGAUR) en la convocatòria competitiva ARMIF 2015. 
cipi per part dels alumnes. En el sentit epistemològic, és preguntar si el que s'ensenya és racionalment justificable i, en última instància, digne que l'alumne el conegui, el cregui o l'entengui (Fenstermacher, 1989, p. 158).

Hi ha un gran nombre de publicacions sobre com ensenyar als alumnes i com ensenyar als mestres a fi que siguin bons mestres. Les podem trobar sota diferents denominacions: «bones característiques» (Thompson et al. 2004), «qualitats» (Rice, 2003; Lewis, Zhang i Watkins, 2007), «ensenyança eficaç» (Brophy i Good, 1986), «mestre qualificat» $\mathrm{i}$ «productivitat» (Harris, 2009).

Altres publicacions suggereixen una particular manera d'ensenyar, tant a la formació inicial com continuada pels mestres (Marland, 1975). En d'altres s'apunta que els mestres han de rebre una formació per competències que els permetin gestionar tots els aspectes de la seva docència: planificació, desenvolupament, transmissió de coneixements, avaluació i oferir feedback als estudiants per a la seva millora. Han d'esdevenir «artesans competents» pel que fa a la docència. També hi ha propostes d'un seguit d'habilitats a adquirir i pràctiques que requeriran d'una autoavaluació, el que comporta una «pràctica reflexiva» (Combs, 1972; Wragg, 1974; Elliott, 1993, citats a Moore, 2004). Tanmateix, trobem recerques que conclouen que per a ser considerat un/a bon/a mestre s'ha de ser carismàtic i, per tant, no es tracta doncs d'una qüestió de formació sinó, més aviat, de mostrar certes qualitats intrínseques de caràcter o personalitat, amb una orientació cap a la cura de la vida del seu alumnat (Bain, 2007).

En els darrers temps, estem evidenciant que el mestre carismàtic és, malgrat tot, el que més èxit té, probablement perquè és el que s'ha mostrat a través de les pel.lícules que mostren mestres exitosos (Professor Holland, El Club dels poetes morts, La classe, Els nois del cor, La llengua de les papallones, El professor Lazhar, Rebel-lió a les aules, etc.) o és una evidència que la tasca de la docència està patint un canvi de concepció. Avui ja no ens fixem tant en les qualitats del bon mestre, sinó en el que demana l'alumne, en els seus resultats acadèmics. Se'ls demanda un coneixement exhaustiu del seu alumant per tal de facilitar el procés d'aprenentatge, els proporcioni un acompanyament abans i després de les sessions de classe, mostrant una actitud amorosa vers l'ensenyament (Brown i Atkins, 2002).

En el present article hem volgut desenvolupar el que configura el rol de mestre des de la vessant ètica, tenint en compte que tots els elements que constitueixen el que s'ha titllat de «bon» mestre formen part del que anomenem «ethos docent». Val a dir que l'ethos docent el relacionarem amb la identitat professional i el lideratge moral, perquè considerem que són dos components clau de la figura del mestre.

\section{L'ethos docent}

L'ésser humà està constituït originàriament (ontològicament) per l'essència racional, però es constitueix dinàmicament (èticament) mitjançant les seves accions lliures, que van conformant la seva manera de ser pròpia, és a dir, el seu caràcter, el seu «ethos». Aquesta manera de ser personal és autoadquirida en l'exercici de la pròpia llibertat. «Dibuixar un ethos docent és emprendre una tasca de definició i re-definició de l'essència mateixa de la docència, del que suposa ser educador» (Altarejos, Ibáñez-Martín, Jordán i Jover, 1998). El ethos o caràcter és, sobretot, una manera de 
ser personal autoadquirida en l'exercici quotidià de la pròpia llibertat. Així, el coneixement de l'ethos només pot realitzar-se mitjançant la via analítica, a través de l'estudi dels seus elements constitutius, els hàbits, és a dir, les diverses actituds que es mostren en les seves accions, resultat del desenvolupament de les diferents operatives humanes tant cognitives com adquirides.

I els hàbits professionals es caracteritzen per: a) ser ineludibles en la seva formació; b) són definitoris operativament de la naturalesa de la professió; c) són elements configuradors del caràcter professional propi; d) són les nocions centrals de la deontologia, entesa aquesta com a coneixement pràctic de l'ethos de la professió.

Resulta interessant la proposta d'Altarejos, Ibáñez-Martín, Jordán i Jover (1998) amb l'objectiu de classificar les virtuts en dos grups: les bàsiques i les superiors. Considera virtuts bàsiques: 1 ) virtuts de la resistència (magnanimitat, longanimitat i paciència); 2) virtuts de la moderació (humilitat, autoestima, afany d'aprendre, altruisme, confiança, tolerància); superiors: 1) justícia (equitat, veracitat o sinceritat, rectitud); 2) prudència (capacitat d'improvisació o perspicàcia, treball en equip, capacitat d'atenció i escolta activa, docilitat). Aquestes virtuts formen un entramat, discernible teòricament però indissociable en la pràctica. Tot i que aquestes virtuts no són exclusives de l'ethos docent, sinó que poden conformar l'ethos d'altres professions, s'han de considerar en el seu conjunt, cap d'elles per separat.

Per altra banda, si ens referim a hàbits com a virtuts, per la potencialitat afegida a l'acció per al futur, podem suggerir quines són aquelles virtuts que s'han de potenciar per part dels mestres i que els ajudin en aquesta finalitat de ser bons mestres. Però el que els clàssics han anomenat «virtuts», hores d'ara, s'anomenen «actituds». Així, definim les actituds com aquelles predisposicions, apreses i relativament fixes que orienten la conducta, que previsiblement es manifestarà en una situació u objecte determinat; l'actitud, doncs, és una predisposició conductual, no innata, sinó adquirida per la persona al llarg de la vida i en base a les seves experiències (Puig, 1995, p. 125). Les actituds s'interioritzen i acaben formant part de l'ethos, com un caràcter moral que es forja amb ajuda de la comunitat en la que viu (Altarejos, Ibáñez-Martín, Jordán i Jover, 1998, p. 127).

Les actituds bàsiques que assumeix el mestre com a professional constitueix el seu ethos professional, el caràcter que s'ha anat forjant al llarg dels anys en el seu Iloc de treball. En relació a les actituds (García, Gozálvez, Vázquez i Escámez, 2010, p. 100) el mestre ha de conrear algunes que l'ajudaran a: a) situar-se en el món: apertura, creativitat, imaginació; b) situar-se davant seu: honestedat i sinceritat, valentia, modèstia; c) situar-se davant l'altre: proximitat, escolta activa, compromís; d) situar-se en la relació amb els altres: interès per l'altre, confiança en els recursos i possibilitats de l'altre, acceptació de l'altre tal qual és; e) situar-se en el treball: cooperatiu, participant, negociador; f) manera de valorar les idees, opinions i conductes: flexible, tolerant, respectuós; g) manera de percebre's i ser percebut: coherent, seré, equilibrat.

En un mateix sentit, Martínez Navarro (2010) proposa una ètica docent basada en l'examen de les principals relacions que formen part de l'activitat del mestre: la relació amb ell mateix; amb el context ètic-polític que li ha tocat viure; amb els/les 
alumnes; amb el centre educatiu on treballa; amb el currículum que ha d'ensenyar; amb els col-legues; amb les famílies; amb la comunitat, i amb la direcció del centre.

En relació amb ell mateix, el mestre ha de ser conscient de què l'ha motivat a escollir aquesta professió, si es tracta de vocació o bé ha estat una elecció induïda per altres circumstàncies. És possible, però, que tot hi havent escollit de forma conscient aquesta professió, puguin sorgir dubtes en certs moments que poden ser fruit de la pròpia inquietud de fer les coses bé. En el context social i educatiu actual, la tasca del mestre és força complexa. Així, és molt important fer aquest exercici d'auto-coneixement, sobretot a nivell ètic o moral, però també a nivell filosòfic, polític i religiós, si escau.

Pel que fa a la seva relació amb el context ètic-polític i amb les seves opcions ètiques, ha de tenir en compte que viu en una societat oberta, plural i democràtica, on s'han de respectar els drets humans de totes les persones, reconeixent la seva dignitat (Escámez, Pérez, García, Llopis, 2007), per tal de desenvolupar una vida plena segons el model que lliurement escullin, la qual cosa implica una clara adhesió a l'ètica cívica, on hi ha uns valors ètics a compartir. Haurà de distingir quan ha de tenir una actitud neutral o bé una actitud bel-ligerant davant les situacions quotidianes a l'aula i al centre educatiu (Trilla, 1992). Tanmateix, cada mestre, en funció de les seves particulars creences, adoptarà un estil propi de docència que, en la majoria de casos, serà èticament acceptable.

Un dels aspectes més importants que ha de tenir present el mestre és la relació o el vincle que genera amb l'alumnat. Aquesta relació és clau en l'ètica professional dels mestres de totes les èpoques i d'arreu. Ara bé, no podem especificar com ha de ser la relació mestre-alumne sense tenir en compte el context on esdevé, definit unes línies abans. L'objectiu principal del mestre, en principi, és promocionar l'autonomia dels seus alumnes, entesa com la capacitat per orientar-se pel propi pensament i les pròpies decisions en els assumptes que li pertoquen. El desenvolupament de l'autonomia va directament relacionat amb el procés de fer-se a si mateix. Com va dir Gadamer (2000), «educar consisteix fonamentalment en educar-se», quelcom més que acumular experiències d'aprenentatge.

També hem d'afegir el següent tipus de relació que hem esmentat: la del mestre amb el currículum a transmetre i les lleis educatives que, sens dubte, condicionen la seva tasca, fins el punt que sovint no és possible un exercici ètic de la docència sense saber quins són els continguts a ensenyar i per què, com ensenyar-los, quan, quins recursos són necessaris i com s'avaluarà tot el procés d'aprenentatge. En aquesta relació mestre-currículum apareix un element important, la «llibertat de càtedra» per a prendre decisions tècniques i ètiques idònies a cada moment, sense perdre de vista la finalitat de la tasca docent, és a dir, incrementar l'aprenentatge dels alumnes per a ser millors persones i millors ciutadans.

\section{Ethos docent i identitat professional}

La identitat professional i l'ethos docent solen ser el resultat d'un llarg procés per construir una manera de sentir-se mestre, al mateix temps que donar sentit al seu exercici quotidià (Bolívar, 2007). Són el resultat (sempre provisional) d'un procés que integra diferents experiències de l'individu al llarg de la seva vida, en funció de les 
circumstàncies que li toqui viure, tant personals com professionals. Per descomptat, tenen un paper clau en aquest procés les experiències escolars viscudes com a alumnes, el possible atractiu de la docència, el seu primer modelatge en la formació inicial, els inicis en el seu exercici professional; tot això, el condicionarà positivament o negativament.

La identitat professional docent, avui més que mai, és un element clau per lluitar contra tots aquells canvis socials que s'estan produint pel que fa als mestres. Aquesta no sorgeix de manera automàtica, sinó que es va construint a través d'un procés complex, dinàmic i sostingut en el temps, és a dir, es construeix des de l'inici $i$ es perllonga durant tota la seva trajectòria professional. El concepte d'identitat docent, si més no, correspon a un tipus d'identitat collectiva que neix d'«una construcció individual referida a la història del docent i a les seves característiques socials, però també d'una construcció collectiva vinculada al context en el qual el docent treballa» (Vaillant, 2010); per tant, depèn de la formació inicial i de la socialització professional en les condicions d'exercici de la pràctica professional. Per això, és una construcció singular, lligada a la seva història personal i a les múltiples pertinences que arrossega (socials, familiars, escolars i professionals). En segon lloc, és un procés relacional, és a dir, una relació entre si i els altres, d'identificació i diferenciació, que es construeix en l'experiència de les relacions amb els altres (Cattonar, 2001).

Quan ens referim a la identitat professional del docent, ho fem al significat que aquest li dona al seu saber i a la valoració que li concedeix a la relació amb els seus alumnes (Davey, 2013). Però també identifiquem el mestre a partir del que realitza, de les seves accions professionals, i l'acció primordial és educar responsablement els seus alumnes. Educar responsablement exigeix tenir consciència del context social i cultural que envolta i influeix en la manera de com es porta a terme la tasca educativa. Tant és així que podríem dir que l'educació actual és el resultat de les diferents influències externes que envolta la tasca del docent, i el nivell d'influència del medi social és cada vegada més complex de determinar a causa de la rapidesa amb què es mou avui la informació, juntament amb els avenços científics i tecnològics.

Mentre la societat es desplaça vertiginosament, l'educació va a un ritme lent que impedeix seguir els canvis socials i culturals. De tal manera que el compromís per una adequada actualització és de vital importància, advertint, això sí, que tota preparació va quedant obsoleta de forma molt ràpida, la qual cosa ens exigeix reconèixer que una dimensió fonamental de l'exercici professional del docent és la formació continuada, que esdevé un requisit permanent per a la seva tasca educativa ara com ara. Ja no n'hi ha prou amb dir que l'experiència i el que aprenem d'ella és l'única cosa que es requereix, perquè l'experiència no supleix la necessitat d'una formació permanent (Buxarrais, 1997), ans el contrari, la potència i li dona el seu sentit pràctic.

Tanmateix, la fita de major rellevància en la construcció de la seva identitat es produeix durant el pràcticum, ja que és l'escenari en el qual es posen en qüestió les seves idees, expectatives, preconcepcions. Acompanyar la transició entre la idealització inicial d'escola i mestre cap a la recomposició de la professionalitat i la construcció de la seva pròpia identitat, són funcions clau de la formació inicial (Jarauta i Pérez, 2017). 
En aquest sentit, la formació inicial dels mestres pot ser vista com un punt de partida ideal, no només per millorar la consciència de la necessitat de desenvolupar la identitat, sinó també com l'esfera on s'estan registrant canvis en la identitat professional. És un espai de formació del caràcter dels mestres (Tey i Gustems, 2016). Sense això, l'exploració de la pròpia identitat durant la formació de docents no sempre és intencional i actualment promoguda explícitament en els programes de formació docent (Ubani, 2016).

Al costat de l'adquisició d'un coneixement personal per a l'ensenyament, el coneixement d'un mateix i el desenvolupament de la identitat constitueixen peces clau en el procés de convertir-se en mestre (Connelly i Clandinin, 1990). Així que construir una identitat professional li ha de comportar una reflexió sobre alguns aspectes de la seva pràctica professional, com per exemple: quines son les seves actituds davant l'aprenentatge dels alumnes; sobre les seves concepcions d'ensenyar i aprendre; entendre que l'aprenentatge i l'ensenyança és un camí amb moltes parades, no una destinació final; adonar-se que cada persona té un potencial d'aprenentatge, i anar millorant la seva capacitat de produir un aprenentatge actiu en el seu alumnat, entre d'altres.

El mestre en si mateix segueix exercint un paper preponderant en l'educació i en la conformació de la personalitat moral (Buxarrais, 1997) dels alumnes ja que compleix una funció fonamental en el procés identitari de qui està educant; per tant, la seva tasca ha de realitzar-la amb la major professionalitat possible (Martínez i Tey, 2007). El professionalisme del mestre serà l'element fonamental que atorga el segell a la seva pròpia identitat, el que es pot traduir com la seva identitat moral.

Ens referim llavors a una identitat professional i moral del mestre, perquè la funció no es limita a l'ensenyament de continguts sinó a educar els alumnes a fi que siguin amos de si mateixos i constructors del demà. Hores d'ara, el mestre està exigit a «orientar, planificar, socialitzar, dinamitzar, organitzar, seleccionar i elaborar recursos i avaluar, etc.» (Sarramona, 2000, p. 84). Davant d'aquestes demandes sembla que hauria de ser un «súperprofessional» posseïdor de tots els coneixements, habilitats, competències i valors que existeixen. Però clarament la realitat és una altra, i feliçment una altra, perquè totes aquestes demandes descrites provoquen en el mateix docent una autoimatge que no és la real però que, en moltes ocasions, assumeix aquesta situació com una cosa inherent a la seva professió i, per tant, formarà part en la manera de comprendre's a si mateix. Es veurà una identitat fràgil i vulnerable, que esdevindrà una identitat professional carregada de frustracions; els efectes negatius afecten la seva autoestima, el seu autoconcepte i, finalment, li provoquen un malestar docent permanent (Esteve, 1994).

La recerca d'un ideal de professionalitat va assentant les bases d'una identificació moral i professional. Caldria llavors atendre les motivacions, il.lusions i creences que el docent té de la seva professió i en quin posicionament personal es troba davant d'aquesta. Si més no, un primer desafiament que consisteix a saber reconstruir i ressignificar la seva pròpia identitat professional com una tasca constant qüestionant el que es pensava i es creia fins ara, amb un esperit crític d'autoavaluació permanent. 


\section{Ethos docent i lideratge moral}

Un dels components de l'ethos docent (Greenfield, 2004) és el lideratge moral. La literatura especialitzada determina que el líder moral ha de complir amb certs requisits o posseir certes qualitats; per exemple: ser digne de confiança i complir amb les seves responsabilitats, treballar per al bé comú; promocionar i defensar les lleis, costums i valors del context; apreciar positivament la diversitat del país; contribuir a la millora de la dignitat de les persones que té al seu voltant; possibilitar als seguidors que desenvolupin tot el seu potencial; practicar la justícia; tenir cura de l'ambient; practicar la meditació i el silenci; tenir cura de la imatge i la presència; practicar la formació permanent; ser entusiasta; respectar els valors universals, i no només elevar el nivell de la conducta humana, sinó de permetre educar, persuadir i aconseguir una cooperació conscient (Torres Reyes, 2012).

El lideratge moral consisteix, doncs, en el procés de formar i desenvolupar valors i principis morals i conduir els seguidors (l'alumnat) a actuar d'acord amb aquests valors morals, liderar de manera que es respectin els drets i la dignitat de les persones, a més de tenir una visió clara de la societat que un desitja, i d'algunes de les estratègies per transformar-la. A partir d'aquesta visió i d'aquestes estratègies, podrà lluitar activament per construir una societat millor i assegurar la igualtat d'oportunitats per als alumnes desavantatjosos, tot procurant la justícia social (Resick et al. 2011). Sergiovanni (1984) va designar el lideratge moral com el cor del lideratge, perquè l'esmentat cor reflecteix els valors, les creences i els desitjos del lideratge moral; per tant, el cervell del líder reflectirà la seva capacitat moral i es perfilarà d'acord amb el seu cor.

A més, ser un líder moral comporta un profund compromís personal d'esforçarse per la transformació individual per mitjà del desenvolupament i l'exemplificació d'una vida basada en principis morals, particularment en la lluita per una transformació col-lectiva per mitjà d'accions que promoguin la unitat i la justícia. Però, encara que atorguem al docent aquest paper, en primer Iloc, aquesta capacitat de lideratge moral hauria de ser exigida als directors dels centres educatius, perquè si exerceixen aquest rol probablement la institució educativa construirà una cultura moral que incidirà en unes pràctiques educatives carregades de valors morals. Per tant, podríem suggerir que els/les directors/es de centres educatius es formin per a aquesta comesa.

Comptem amb exemples reeixits en aquesta qüestió que, encara que provinguin de l'àmbit nord-americà, no són gens menyspreables, com el que porten treballant al Center for Character \& Citizenship, dirigit per Marvin W. Berkowitz, entre d'altres. Els/les directors/es han de preocupar-se no només de la capacitació professional dels docents, sinó de la seva capacitat d'instrucció, la qualitat de l'ensenyament, el rendiment acadèmic, les exigències de rendició de comptes, a més de les necessitats i demandes dels/les nens/es i les seves famílies des del punt de vista dels diversos orígens: cultural, ètnic, lingüístic i econòmic.

No obstant això, la característica fonamental del lideratge moral ha de ser l'esperit de servei, perquè el veritable lideratge moral està exercit per aquell que serveix més a la comunitat, no per qui la domina més. La persona que lluita per servir el bé comú aviat descobreix que és una font de satisfacció profunda i permanent. Tot $\mathrm{i}$ 
que no busca cap benefici personal o reconeixement, el desig de servir l'impulsa a desenvolupar capacitats que li són útils en cada esfera de la seva vida. D'aquesta manera, el servei contribueix al seu propi procés de transformació personal.

Entenem, doncs, que el lideratge moral és un tipus de lideratge que depèn de l'autoritat moral, perquè reflecteix un enfocament de gestió que se centra en el personatge i que s'uneix amb els valors morals. Tanmateix, l'autoritat moral s'atorga, no es pot imposar. Per tant, el lideratge moral «està en els ulls dels seguidors». Ningú és líder perquè es proposi ser-ho, sinó perquè els altres el reconeixen com a tal. En aquest sentit, el lideratge és un fenomen d'atribució, són els altres els que ens atribueixen el lideratge.

Nivells superiors d'autoritat docent són exigibles, però nivells d'autoritat moral, no d'autoritarisme ni de militarisme. L'autoritat moral emana dels que estan en contacte directe amb ella. Així doncs, l'autoritat moral del docent s'aconseguirà quan els docents es percebin com a professionals valorats, estimats i ben pagats, quan treballin en escoles ben equipades, i quan disposin dels recursos humans i materials adequats per a dur a terme les seves tasques pedagògiques.

Rojas i Gaspar (2006) suggereixen desenvolupar cinc competències fonamentals per a convertir-se en docents amb autoritat moral: 1) creïbles perquè sempre compleixen el que prometen; 2) congruents en el que diuen i fan; 3) coordinen accions de manera impecable des de l'escolta, mitjançant peticions, ofertes, declaracions i, per descomptat, promeses; 4) competents dissenyadors dels estats d'ànim d'alegria, tranquil.litat i laboriositat com a característiques de les seves aules; 5) competents observadors de les emocions i estats d'ànim dels seus estudiants i detenen els estats emocionals destructius. Una disposició fonamental per constituir-se en autoritat moral té a veure amb un conjunt de competències que han de tenir o desenvoluparse, entre les que destaquem: l'escolta activa, la coherència entre el que un diu i el que fa, complir les promeses i ser sensible a les emocions i els estats d'ànim dels que ens envolten (Tey, 2011).

En primer Iloc, l'escolta activa significa escoltar l'altre de veritat, entenent, coneixent a fons les seves preocupacions. Els docents líders o models solen mostrar una escolta sincera i profunda i, d'aquesta manera, es constitueixen en autoritat moral. En paraules d'Echeverría (2005), els docents han de sentir, interpretar i inquirir. Sentir vol dir assegurar-se que escolto tot el que el/l'alumne/a diu. Interpretar vol dir preguntar-se per què l'alumne diu el que diu o pregunta el que pregunta, què és el que ha comprès, què és el que es considera sense sentit o dissonant del que ha dit el mestre o els altres estudiants, a més des de quina emoció o estat d'ànim ho diu. Per inquirir, el docent ha d'indagar. Es tracta que pregunti a l'estudiant, mirant-li als ulls, i amb tendresa, què li preocupa. Només quan el docent aconsegueixi una bona interpretació del que l'estudiant ha dit, ha d'oferir una explicació. I si no sap què respondre, ha de dir-ho amb sinceritat.

Així doncs, les habilitats socials i emocionals són crucials per a l'èxit escolar, per tant, un líder moral ha de dominar-les. La investigació recent suggereix que la intel-ligència emocional es desenvolupa gràcies a les experiències vitals a l'escola, on també es desenvolupa la intel-ligència acadèmica (Zins et al., 2004). Ja Goleman (2004) va advertir: «Els programes d'aprenentatge social i emocional aplanen el camí 
per a un millor aprenentatge acadèmic, ensenyen als nens i les nenes habilitats socials i emocionals íntimament vinculades amb el desenvolupament cognitiu». Les habilitats socials i emocionals faciliten la vida quotidiana, afectant les relacions i l'assoliment d'habilitats com la comunicació, la resolució de conflictes, la presa de decisions i la cooperació (Catalano, Haggerty, Oesterlé, Fleming, i Hawkins, 2004). Existeixen gran quantitat de referències que afirmen que els programes que s'ocupen de les competències socials i emocionals són eficaços en la prevenció dels problemes de conducta (Durlak i Wells, 1997; Wilson, Gottfredson i Najaka, 2001), incloent l'ús de drogues (Tobler et al, 2000) i la violència (Greenberg i Kusche, 1998). A més, l'aprenentatge social i emocional és un potent predictor de bons resultats acadèmics (Elias et al., 2006; Elias, Parker, Kash, Weissberg, i O’Brien, 2007).

Per tant, els docents han de desenvolupar les habilitats socials i emocionals, disposar de competències com la de la construcció de confiança i la de la creació d'estats d'ànim. Crear un estat d'ànim vol dir generar una atmosfera de cordialitat, pau i civilitat on el respecte estigui implícit en tot moment. És bàsic adonar-se que les emocions i els estats d'ànim formen part de les aules tant com l'aprenentatge, tant o més que la comprensió de les assignatures, que l'assoliment cognitiu. Les emocions i els estats d'ànim formen part del que són els nostres estudiants i del que som nosaltres. Hem d'aprendre a gestionar-les. Perquè sabem que determinades emocions, les negatives com el desànim, la tristesa o el pessimisme, poden tancar possibilitats d'acció. Si els estudiants estan alterats és molt difícil treballar a l'aula. Per tant, cal integrar l'educació emocional en la formació inicial del professorat per a tots els nivells i etapes educatives.

També l'autoconeixement és una dimensió que el líder moral ha de procurar desenvolupar, perquè dinamitza els altres aspectes del lideratge. Treballar sobre un mateix, sobre quins són els meus límits, els meus compromisos, la meva visió, els meus valors, etc. Perquè si un no es coneix a si mateix, li resultarà molt difícil afrontar les situacions i respondre davant d'elles.

L'analfabetisme de l'autoconeixement dona com a resultat el fet de no poder treballar amb els elements imprescindibles per afrontar situacions que es donen en la vida de l'aula. Heifetz i Marty (2002), en els seus estudis sobre lideratge, parlen de vincular acció amb reflexió, o bé, acció reflexiva. Utilitzen la metàfora d'una sala de ball. El docent ha de ser capaç de simultaniejar estar a la pista de ball i a la grada. En el moment d'exercir la seva funció de líder moral està actuant, orientat per uns objectius. Però, si no és capaç de separar-se un instant de l'aula i prendre distància, per a disposar d'una grada on accedir a una visió diferent, serà difícil que no es converteixi en un pur activista, preparant pràctiques educatives una per una, sense una anàlisi de la seva validesa i pertinència. A més, cal reflexionar sobre qui marca el ritme, si és el mateix docent o si ve imposat per una altra instància, el director, la família, la societat, etc.

Els valors estan íntimament incrustats a l'escola i la vida de l'aula (Campbell, 2003; Fenstermacher, 1990; Hansen, 1993). Els mestres transmeten valors implícitament quan seleccionen o exclouen temes, quan insisteixen en certes respostes com a correctes, quan animen els estudiants a buscar la veritat d'un assumpte, i quan s'estableixen les rutines de l'aula, com formen els grups per a les activitats coope- 
ratives, com estableixen les normes de disciplina i com es compleixen o les fan complir, i com fomenta l'excel-lència. Els mestres modelen certes formes de la vida social dins de les aules i també influeixen en com configuren els seus valors els estudiants, les experiències de pertinença a la comunitat escolar. Els valors morals saturen la vida quotidiana de les aules (Bryk, 1988; Goodlad, 1992; Hansen, 1993; Strike, 1996).

Sabem que les normes que s'estableixen a l'aula són portadores de valors, perquè els valors s'expressen a través dels sistemes normatius vigents en la societat, els quals representen els horitzons de comportament que es presenten com a desitjables o obligatoris per als membres d'un grup social determinat, les «virtuts». Així doncs, a través dels comportaments que considera obligatoris o desitjables per ser observats pels seus alumnes, el docent estableix una normativa a la seva aula i en altres espais de la vida escolar, filtrant en diferents plans valors socials, orientacions explícites o implícites de la institució escolar, i també els seus valors personals. Per això, resulta pertinent preguntar-nos quines són les normes que els docents líders morals estableixen en els diferents espais escolars i a què al-ludeix el contingut d'aquestes normes. D'aquesta manera, podrem inferir quins valors hi ha al darrere, donant-los raó de ser.

No obstant això, no tot queda en les normes i en el seu contingut. Mitjançant el comportament afectiu que el docent manifesta en diferents espais formals i informals, les pròpies regulacions que dibuixen la relació amb els alumnes, des de la seva posició d'autoritat i líder moral, posa en pràctica valors propis en permetre determinada forma de tracte i de manifestar afectes de diferent signe -que poden anar des de la felicitació fins al menyspreu-cap a la persona dels seus alumnes.

\section{Evidències empíriques}

\section{Participants}

Vàrem dur a terme una recerca que ens va mostrar quines eren les característiques del que es considerava un «bon mestre» i que aporta dades interessants que corroboren algunes de les qüestions teòriques tractades.

Els participants en la recerca varen ser mestres amb més de deu anys d'experiència docent en diferents nivells educatius, 6 homes i 13 dones, d'edats compreses entre els 30 i 65 anys, procedents d'escoles públiques i privades de Catalunya i considerats exemple de bons docents per part dels seus iguals.

\section{Instruments de la recerca}

Es van dur a terme entrevistes semiestructurades de forma presencial, durant el curs escolar 2017-2018. L'entrevista constava de 6 preguntes: 1) Per què vas voler ser mestre?, 2) Quines característiques creus que ha de tenir un bon mestre?, 3) Quins d'aquests trets creus que tens tu?, 4) Circumstàncies educatives actuals, 5) Propostes per a la formació universitària, 6) En quin grau et va ajudar la formació universitària?.

En el present article ens hem centrat en dues de les preguntes realitzades en l'entrevista: 1) «Quines característiques ha de tenir per a tu un/a bon/a mestre/a des del punt de vista del caràcter, de la seva manera de ser i estar a l'aula ? (Les pots 
enumerar)», i 2) «Quins d'aquests trets creus que tu posseeixes? Per què?». La primera de les preguntes està relacionada amb la seva perspectiva sobre l'ethos professional i la segona, sobre la seva identitat professional i moral.

\section{Resultats}

Les entrevistes van ser transcrites, analitzades i categoritzades. A partir d'aquí, classifiquem les respostes i per detallar quines són les característiques (virtuts) que mestres experimentats creuen que hauria de tenir el que ells consideren «un bon mestre». Els resultats de les entrevistes es van analitzar segons variables demogràfiques i professionals dels entrevistats i es comparaven amb els resultats obtinguts en investigacions similars. A la següent taula presentem els resultats obtinguts amb l'anàlisi de les respostes a aquestes dues preguntes.

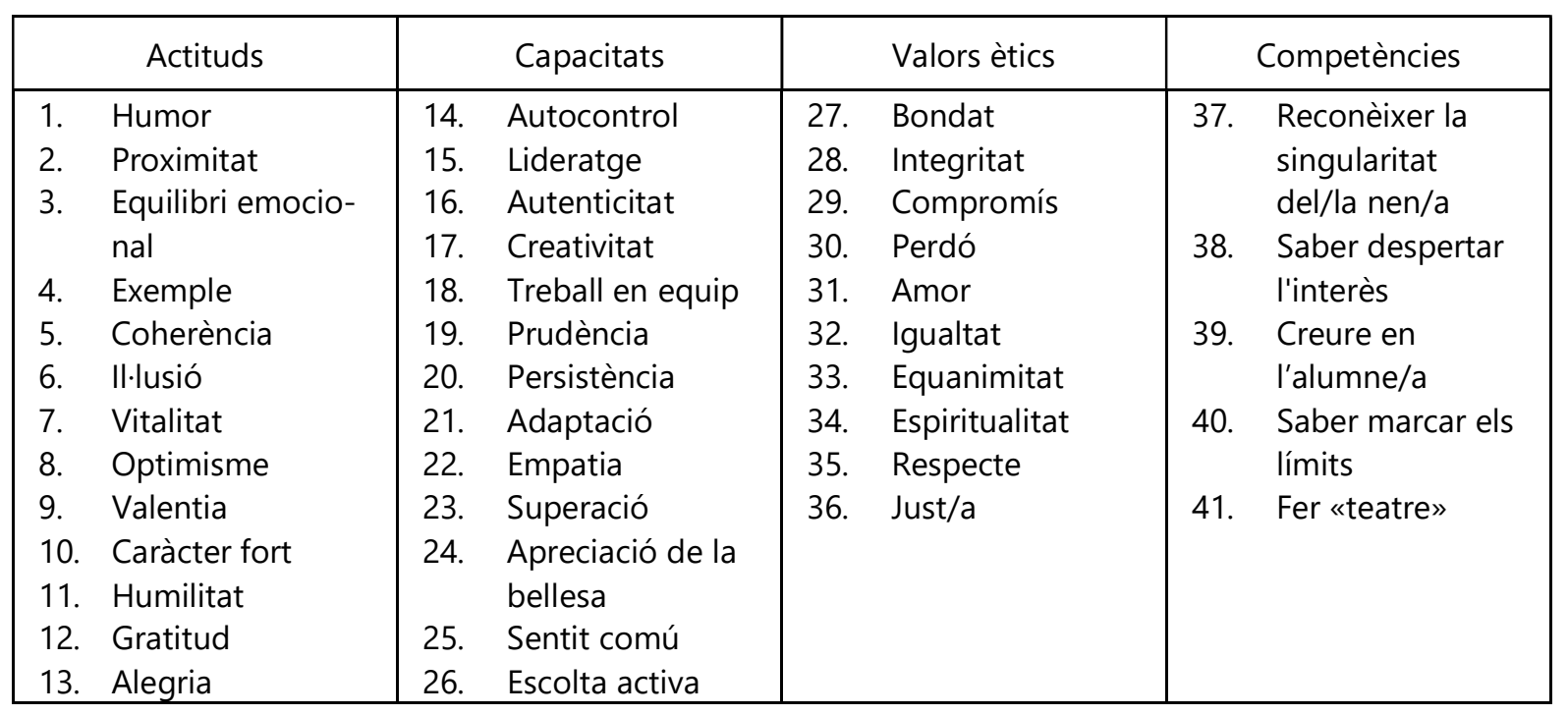

Podríem distingir el caràcter personal o les seves actituds o característiques de personalitat, i les del seu paper com a mestre: capacitats, valors ètics i competències. Així, veiem un perfil del docent que es caracteritza fonamentalment pel seu desig de tenir cura, motivar, ajudar i inspirar els seus alumnes. Posseïdor d'unes emocions, accions i reflexions difícilment mesurables (Constanti i Gibbs, 2004, p. 247), però que són la base de la seva professió. Els mestres, d'altra banda, mostren un compromís personal molt fort cap a la seva professió i les seves emocions ajuden a construir la seva identitat (Nias, 1989; Zembylas, 2016). Perquè ser mestre implica «nutrició humana, connectivitat, calidesa i amor» (Hargreaves, 1994, p. 175) i les creences individuals de cada professor sobre el seu rol a l'hora d'aplicar l'ètica de la cura, formen una part important de la seva identitat professional. L'ensenyament també està carregat d'emocions positives (Hargreaves, 1998, p. 835) i té lloc en la intersecció de la vida personal i pública (Palmer, 1998). Però per desgràcia el paper que juguen les emocions en el treball dels mestres encara no és acceptat plenament per les polítiques públiques.

\section{Discussió}

Segons l'opinió dels docents entrevistats, els valors, les capacitats i les competències pedagògiques del docent estan lligades a la cura, a generar relacions positives amb 
els alumnes, a promoure la confiança en ells $\mathrm{i}$, sens dubte, a formar en valors morals, encara que sigui de forma implícita, o mitjançant l'exemple (Arthur, 2010; Clement, 2007; Gore et al., 2007 citat a Lovat, 2007; Lovat \& Toomey, 2007; Lovat, Toomey, Clement, Crotty \& Nielsen, 2009; Rowe, 2004; Westcombe-Down, 2009 citats a Boon, 2011). En aquest sentit, Campbell (2008) lamenta que la formació del professorat s'oblida d'ensenyar ètica i considera que aquesta s'hauria d'incloure en els currículums de la formació inicial dels docents. Sense una formació del professorat que ensenyi a desenvolupar les capacitats, actituds o habilitats per educar en valors a les escoles, no serà possible construir un «ethos» docent integral.

La metodologia utilitzada ha posat de manifest que la formació de la identitat professional dels mestres s'assenta, en primer lloc, en les experiències, sabers i representacions de la biografia individual. Per això, els processos formatius s'han d'articular amb la pròpia trajectòria biogràfica, entesos com a processos de desenvolupament individual, de construcció de la persona del professor, com re-apropiació crítica de les experiències viscudes. Referent a això, les històries de vida permeten partir de l'ampli corpus de coneixement i d'experiències que han configurat la pròpia identitat personal, com a base per inserir biogràficament la formació i assentar la identitat professional en la personal (Bolívar, Fernández, Molina, 2005; Goodson, 2004). La formació s'entén, així, com un procés d'apropiació personal i reflexiva, d'integració de l'experiència de vida i la professional, en funció de les quals una acció educativa adquireix significat («formar-se», en lloc de formar el professorat).

\section{Conclusions}

Per adquirir el caràcter de «bon mestre» cal entrenar la persona, qui té com a finalitat prèvia l'elecció lliure d'aquesta professió, en tot el que comporta l'activitat professional que se'n deriva. . Aquesta finalitat consisteix a acompanyar l'altre en la seva millora, mitjançant l'exemplaritat i el domini de la seva matèria. El mestre es deu als seus alumnes $\mathrm{i}$ al col-legi on treballa. Ser mestre significarà tenir cura, servir, fer-se càrrec d'algú vulnerable, però també comporta proporcionar continguts, saber. Educar es converteix, d'aquesta manera, en un acte de respecte i amor a la matèria que un imparteix, a la professió que un exerceix i a la qual ha de representar dignament. Educar també és un acte contemplatiu, amb la distància oportuna, amb la mirada atenta que és el respecte de qui, per posició, anys, coneixement i experiència té el privilegi de veure.

És necessari formar docents crítics que contribueixin a la construcció d'una societat més justa i democràtica. Cal que aquests duguin a terme un autodiagnòstic per veure què és el que poden millorar de cara a desenvolupar la seva feina amb professionalitat: capacitat d'escolta, proximitat amb els alumnes, sentit de l'humor, saber motivar els seus alumnes a fi que aprenguin de maneres diverses, ser capaç de relacionar l'aprenentatge amb l'experiència, de mantenir un ambient de classe organitzat, conèixer bé la seva matèria, crear ambients propicis per a l'aprenentatge de valors ètics, entre d'altres. Els programes de formació continuada per a docents en exercici han de procurar proporcionar propostes psicopedagògiques que no depenguin només d'un determinat corrent de moda, sinó oferir una formació de qualitat que tingui realment una incidència en la innovació educativa. 
Després de més de dues dècades treballant en l'àmbit de l'educació en valors i analitzant els resultats obtinguts, apostem per un model d'educació en valors en el que el «bon» mestre integri de forma transversal dimensions que es contemplen en la perspectiva de l'educació del caràcter (Lickona, 1983) i l'educació de la cura (Noddings, 2009). Si volem formar «bons» mestres no podem deixar d'atendre aquestes dues dimensions de la persona: la volitiva i l'emocional. En el model de «la construcció de la personalitat moral» (Buxarrais, 1997) plantegem la potenciació de tres dimensions: la cognitiva, l'emocional i la volitiva. En aquest cas, fomentar el lideratge moral, però, implica bàsicament potenciar la dimensió emocional i la volitiva, perquè la cognitiva ja estarà integrada en les altres dues.

Sabem que les decisions en la vida es prenen gràcies als hàbits que hem adquirit, en forma de rutines, pel seu valor pràctic. Quan es té un «bon caràcter», el que s'espera és que es prengui una decisió intel.lectual clara per fer alguna cosa, es vulgui fer-ho i després es faci, perquè s'està motivat per emprendre les coses bones $i$ rebutjar les dolentes, fins i tot quan s'està sotmès a la pressió d'un ambient advers.

El paper del mestre des d'aquesta perspectiva (Nucci i Narváez, 2008) no és només ajudar l'alumne a adquirir determinats comportaments, sinó que ha de contribuir al fet que desenvolupi uns hàbits de cap, cor i acció que capacitin la persona per créixer i desenvolupar-se com a tal. Perquè el docent ha de plantejar el seu paper com a model i líder moral, des del respecte i amor, ha de corregir i guiar els seus alumnes en els seus errors i conductes incorrectes i encoratjar-los en els seus encerts i comportaments positius. En aquesta perspectiva, el lideratge moral és un dels sis elements (Puig, 2012) que configuren la cultura moral positiva en un centre educatiu, constituiida per un conjunt de regles no escrites a l'escola: valors, normes i hàbits, creences i símbols. És així com la cultura moral de la institució es defineix no només com la filosofia organitzacional del centre, sinó en base als comportaments dels professors, en les seves pràctiques educatives.

\section{Referències}

Altarejos, J.A., Ibáñez-Martín, J.A., Jordán, J.A. i Jover, G. (1998) Ética docente. Barcelona, Ariel.

Argos, J. i Ezquerra, P. (Eds.) (2013) Liderazgo y Educación. Santander, PubliCanEdiciones Universidad de Cantabria.

Bain, K. (2007) Qué hacen los mejores profesores universitarios. Valencia, Universitat de València.

Ball, S. J. i Goodson, I. (1985) Teachers lives and careers. Lewes, Falmer Press.

Bernal, A. (2003) «La construcción de la identidad personal como proyecto de educación moral. Supuestos teóricos y delimitación de competencias». Revista Teoría de la Educación, 15, Salamanca, Ediciones Universidad de Salamanca, p. 129-160.

Bernal, A., Jover, G., Ruiz, M. i Vera, J. (2013) «Liderazgo personal y construcción de la identidad profesional del docente», a Argos, J. i Ezquerra, P. (Eds.) Liderazgo y Educación. Santander, PubliCan-Ediciones Universidad de Cantabria, p. 17-42.

Bolívar, A.; Fernández, M. i Molina, E. (2005) «Investigar la identidad profesional del profesorado: Una triangulación secuencial». Forum: Qualitative Social Research, $6(1)$, p. $129-141$. 
Bolívar, A. (2007) «La formación inicial del profesorado de secundaria y su identidad profesional». Estudios sobre Educación, 12, p. 13-30.

Boon, H. (2011) «Raising the Bar: Ethics Education for Quality Teachers American». Journal of teacher education, 36, (7), p. 76-93

Bryk, A.S. (1988) «Musing on the moral life of schools». American Journal of Education, 96(2) p. 256-290.

Brophy, J. i Good, T. (1986) «Teacher behaviour and student achievement» a M. Wittrock (Ed.) Handbook of research on teaching. New York, Macmillan, p. 376391.

Brown, G. i Atkins, M. (2002) Effective Teaching in Higher Education. London, Roudledge.

Buxarrais, M.R. (1997) La formación del profesorado en educación en valores. Propuesta y materiales. Bilbao, Desclée de Brouwer.

Buxarrais, M.R. (2011) «De l'educació en valors a l'educació per a la ciutadania», a Buisán, C., Echebarria, I. i Martínez, M. (Coords.) Reflexions sobre l'educació i el professorat, Barcelona, Institut de Ciències de l'Educació, p. 67-72.

Buxarrais, M.R. i Martínez, M. (2009) «Educación en valores y educación emocional: Propuestas para la acción pedagógica». Education in the Knowledge Society (EKS) 10(2), p. 320-335. Disponible a:

http://revistas.usal.es/index.php/eks/article/view/7519

Cabo, C. (2006) «Pensar y pensarse: un deber para mejorar la práctica». Revista Iberoamericana de Educación, 39 (2), p. 1-8.

Campbell, E. (2003) The Ethical teacher. Berkshire, Open University Press.

Campbell, E. (2008) «The ethics of teaching as a moral profession». Curriculum Inquiry, 38(4), p. 357-385.

Carr, D. (2006) «Professional and personal values and virtues in education and teaching». Oxford Review of Education, 32, p. 171-183.

Catalano, R.F., Haggerty, K.P., Oesterlé, S., Fleming, C.B., i Hawkins, J.D. (2004) «The importance of bonding to school for healthy development: findings from the Social Development Research Group». Journal of School Health. 74(7), p. 252261.

Cattonar, B. (2001) «Les identités professionnelles enseignantes. Ebauche d'un cadre d'analyse». Cahiers de Recherche du GIRSEF, 10 (mars). Recuperat el 29 d'octubre de 2019, de https://halshs.archives-ouvertes.fr/halshs-00603566/document

Combs, M.E. (1972) «Some basic concepts for teacher education». The Journal of Teacher Education, 23(3), p. 286-290. University of Florida, Center for Humanistic Education.

Connelly, F.M. i Clandinin, D.J. (1990) «Studying Teachers' Live», a Pinar, W.F., Reynolds, W.M., Slattery, P. i Taubman, P.M. Understanding curriculum. An Introduction to the Study of Historical and Contemporary Curriculum Discourses. New York, Peter Lang.

Constanti, P. i Gibbs, P. (2004) «Higher education teachers and emotional labour». International Journal of Educational Management, 18(4), p. 243-249.

Cruickshank, D. R., Jenkins, D. B. i Metcalf, K. K. (2003) The act of teaching. New York, NY, McGraw-Hill. 
Davey, R. (2013) The professional identity of teachers educators. Career on the cusp? London and New York, Routledge, Taylor \& Francis Group.

Day, Ch. (2006) Pasión por enseñar. La identidad personal y profesional del docente y sus valores. Madrid, Narcea.

Durlak, J. A. i Wells, A. M. (1997) «Primary Prevention Mental Health Programs for Children and Adolescents: A Meta-Analytic Review». American Journal of Community Psychology, 25, p.115-152.

Echeverría, R. (2005) Ontología del lenguaje. Buenos Aires, Granica.

Elias, M. J., O'Brien, M. U. i Weissberg, R. P. (2006) «Transformative leadership for social-emotional learning». Principal Leadership, 7(4), p. 10-13.

Elias, M.J., Parker, S.J., Kash, M., Weissberg, R.P. i O’Brien, U. (2007) Social and Emotional Learning, Moral Education and Character Education: A Comparative Analysis and a Wiew Toward Convergence. https://www3.nd.edu/ dnarvaez/documents/Elias.pdf

Epstein, H. (1978) Ethos and identity. Londres, Tavistock.

Escámez, J., Pérez, C., García, R. i Llopis, J.A. (2007) El aprendizaje de valores y actitudes: Teoría y práctica. Barcelona: Octaedro.

Esteban, F. i Mellén, T. (2016) «¿Por qué quieres ser maestro?, ¿cómo es un buen maestro? Ideas para la formación universitaria». Bordón. Revista de Pedagogía (Madrid, Sociedad Española de Pedagogía), 68 (2), p. 185-198. Disponible a: https://recyt.fecyt.es/index.php/BORDON/issue/view/2734 [accés: 13.9.2017].

Esteve, J. M. (1994) El malestar docente. Barcelona, Paidós.

Fenstermacher, G.D. (1989) «Tres aspectos de la filosofía de la investigación sobre la enseñanza», a M. Wittrock (Comp.), La investigación de la enseñanza I. Enfoques, teorías y métodos. Barcelona, Paidós, p. 149-179.

Fenstermacher, G. D. (1990) «Some moral considerations on teaching as a profession». A John I. Goodlad, Roger Soder i Kenneth A. Sirotnik (eds.), The Moral Dimensions of Teaching. Jossey-Bass Publishers, p. 130-151

Gadamer, H. G. (2000) La educación es educarse. Barcelona, Paidós.

García, R., Gozálvez, V., Vázquez, V. i Escámez, J. (2010) Repensando la educación. Cuestiones y debates para el siglo XXI. Valencia, Brief Ediciones.

Gatti, G. (2001) Ética de las Profesiones Formativas. Bogotá, Ediciones San Pablo.

Gil, F., Buxarrais, M.R., Muñoz, J. i Reyero, D. (2013) «El liderazgo educativo en el contexto de aula». A Argos, J.M i Ezquerra, P. (Eds.) Liderazgo y Educación, Santander, PubliCan-Ediciones Universidad de Cantabria, p. 99-124.

Goleman, D. (2004) Emotional Intelligence. USA, Editorial Random House.

Goodlad, J. (1992) «The moral dimensions of schooling». Journal of Moral Education. 21(2) p. 87-98.

Goodson, I. (Ed.) (2004) Historias de vida del profesorado. Barcelona, Octaedro-Eub.

Greenberg, M. T., i Kusche, C. A. (1998). «Blueprints for violence prevention», The PATHS Project (Vol. 10). Boulder, Institute of Behavioral Science, Regents of the University of Colorado.

Greenfield, W. (2004) «Moral leadership in schools». Journal of Educational Administration, 42 (2), p. 174-196.

Hansen, D.T. (1993) «From the role to person: The moral layeredness of classroom teaching». American Educational Research Journal, 30(4), p. 651-674. 
Hansen, D.T. (2001) Llamados a enseñar. Barcelona, Idea Books.

Hargreaves, A. (1994) Changing teachers, changing times: Teachers' work and culture in the postmodern age. London, Cassell.

Hargreaves, A. (1998) «The emotional practice of teaching». Teaching and Teacher Education, 14, p. 835-854.

Hargreaves, A. (2001) «Emotional geographies of teaching». Teachers College Record, 103, p. 1056-1080.

Hargreaves, A. i Goodson, I. F. (1996) «Teachers' professional lives: Aspirations and actualities» a A. Hargreaves i I. F. Goodson (Eds.), Teachers' professional lives. London, Falmer Press, p. 1-27.

Harris, D. (2009) «Point/Counterpoint: Teacher value-added: Don't end the search before it starts». Journal of Policy Analysis and Management, 28(4), p. 693-699.

Heifetz, R. i Marty, H. (2002) Leadership on the line. Staying alive through the Dangers of Leading. Harvard, Harvard Business School Press.

Jarauta, B. i Pérez, M.J. (2017) «La construcción de la identidad profesional del maestro de primaria durante su formación inicial. El caso de la Universidad de Barcelona». Profesorado. Revista de Currículum y Formación del Profesorado, vol. 21, núm. 1, Enero-Abril, p. 103-122.

Kojastemehr, R. i Takrimi. A. (2009) «Characteristics of effective teachers: Perceptions of the English teachers». Journal of Education and Psychology, 3(2), p. 53-66.

Lewis, F., Zhang, Q., i Watkins, D. (2007) «Conceptions of the good tertiary EFL Teacher in China». TESOL Quarterly 41(4). p. 781-790.

Lickona, T. (1983) Raising good children. New York, Bantam Books.

Lovat, T. (2007) «Values education and quality teaching: two sides of the learning coin», a T. Lovat i R. Toomey (Eds.), Values education and quality teaching: The double helix effect. Terrigal, NSW, David Barlow Publishing, p. 1-12.

Marland, M. (1975) The craft of the classroom: a survival guide to classroom management in the secondary school. London, Heinemann Educational Books.

Martínez, M.; Tey, A. (2007) «El profesorado: profesión y compromiso ético». A Profesorado y otros profesionales de la educación. Madrid, Octaedro, p. 37-76.

Martínez Navarro, E. (2010) Ética profesional de los profesores. Bilbao, Desclée de Brouwer.

McBer, H. (2000) Research into Teacher Effectiveness. http://ateneu.xtec.cat/wikiform/ wikiexport/_media/formgest/equips_directius/st02/bloc_5/5_rr216investigacio_ professors_eficients.pdf

Mendoza, M.R. i Ortiz, C. (2006) «El liderazgo transformacional. Dimensiones e impacto en la Cultura Organizacional y Eficacia de las Empresas». Revista Facultad de Ciencias Económicas: Investigación y Reflexión, Colombia. 14, (1), p. 118-134.

Moore, A. (2004) The Good Teacher. Discourses in Teacher Education. London and New York, Routledge, Taylor \& Francis Group.

Nias, J. (1989) «Teaching and self», a M. Holly, i C. McLoughlin (Eds.), Perspectives on teacher professional development. London, Falmer Press, p. 155-172.

Nias, J. (1999) «Teachers' moral purposes: stress, vulnerability and strength», a R. Vanderberge., A.M. Huberman, (Eds) Understanding and preventing teacher 
burnout a source-book of international research and practice. New York, Cambridge University Press, p. 223-237.

Noddings, N. (2009) La educación moral. Propuesta alternativa para la educación del carácter. Buenos Aires, Amorrortu.

Nucci, L. i Narváez, D. (2008) Handbook on moral and character education. Oxford, UK, Routledge.

Nucci, L., Drill, K. i Larson, C., \& Browne, C. (2005) «Preparing preservice teachers for character education in urban elementary schools». Journal of Research in Character education, 3(2), p. 81-96.

Palmer, P.J. (1998) The Courage to Teach: Exploring the Inner Landscape of a Teacher's Life. San Francisco, Jossey-Bass Publishers.

Puig, J.M. (1995) La educación moral en la enseñanza obligatoria. Barcelona, ICEHorsori.

Puig, J.M. (coord.) (2012) Cultura moral y educación. Barcelona, Graó.

Resick, C. J., Hanges, P. J., Dickson, M. W. i Mitchelson, J. K. (2006) «A cross-cultural examination of the endorsement of ethical leadership». Journal of Business Ethics, 63(4), p. 345-359

Resick, C. J., Martin, G. S., Keating, M. A., Dickson, M. W., Kwan, H. K. i Peng, C. (2011) "What ethical leadership means to me: Asian, American and European perspectives». Journal of Business Ethics, 101, p. 435-457.

Revell, L. i Arthur, J. (2007) «Character education in schools and the education of teachers». Journal of Moral Education, 36(1), p. 79-92.

Rice, K. J., (2003) Teacher Quality: Understanding the Effectiveness of Teacher Attributes. Economy Police Institut, Washington DC.

Rojas, A. i Gaspar, F. (2006) Bases del liderazgo en educación. Chile, OE REALC/UNESCO.

Sarramona, J. (2000) Teoría de la educación. Reflexión y normativa pedagógica. Barcelona, Ariel Educación.

Sergiovanni, T. J. (1984) «Leadership and Excellence in Schooling». Educational Leadership, 41 (5), p. 4-13.

Strike, K. (1996) «The moral responsibilities of educators». En J. Sikula, T. Buttery i E. Grifton (Eds). Handbook of research on teaching education. $2^{\text {nd }}$ ed., p. 869-882. New York, Macmillan.

Taylor, Ch. (1994) La ética de la autenticidad. Barcelona, Paidós-ICE/UAB.

Tey, A. (2011) «El desplegament de competències relacionades amb la ciutadania activa». A Prats, E.; Tey, A. i Martínez, M., Educar per a una ciutadania activa. Barcelona, IMEB. Ajuntament de Barcelona, p. 23-33.

Tey, A. i Gustems, J. (2016) «El profesorado en la formación inicial de maestros», en La formación del carácter de los maestros. Barcelona, Publicacions i Edicions de la Universitat de Barcelona, p. 89-98.

Thompson, S., Greer, J.G. i Greer, B.B. (2004) Highly Qualified for Successful Teaching: Characteristics Every Teacher Should Possess. https://www.richlandone.org/cms/lib/SC02209149/Centricity/Domain/158/12_c haracteristics_article.pdf 
Tobler, N., Roona, M., Ochshorn, P., Marshall, D., Streke, A. i Stackpole, K. (2000) "School-based adolescent drug prevention programs. 1998 meta-analysis». Journal of Primary Prevention. 20(4), p. 275-336.

Torres Reyes, A. (2012) Rol y características del liderazgo del docente en la educación superior a distancia en Colombia. Tesi doctoral en Ciències de l'Educació. Universidad de Saragosa.

Trilla, J. (1992) El profesor y los valores controvertidos. Barcelona, Paidós.

Ubani, M. (2016) «RE student teachers' professional development: results, reflections and implications». British Journal of Religious Education, 38 (2), p. 189-199.

Vaillant, D. (2010) «La identidad docente. La importancia del profesorado como persona», a Colén, M.T. i Jarauta, B. Tendencias de la formación permanente del profesorado. Cuadernos de Formación del Profesorado Educación Secundaria. Barcelona, ICE-Horsori, p. 9-24.

Witcher, A., Onwuegbuzie, A. J. i Minor, L. C. (2001) «Characteristics of effective teachers: Perceptions of preservice teachers». Research in the Schools, 8, p. 4557.

Walls, R.T., Nardi, A.H., von Miden, A.M. i Hoffman, N. (2002) «The characteristics of Effective and Ineffective Teachers». Teacher Education Quarterly. Winter, p. 3948.

Wilson, D.B., Gottfredson, D.C., i Najaka, S.S. (2001) «School-based prevention of problem behaviors: A meta-analysis». Journal of Quantitative Criminology, 17 (3), pp. 247-272.

Zembylas, M. (2016) «"La pedagogía del malestar" y sus implicaciones éticas: las tensiones de la violencia ética en la educación de la justicia social». Revista de Educación, 9, pp. 59-76.

Zins, J. E., Weissberg, R.P., Wang, M.C. i Walberg, H.J. (2004) Building academic success on social and emotional learning: what does the research says? New York, Teachers College Press. 
Resumen: Responder a la pregunta de cómo se hace un buen maestro es bastante complejo, porque cada uno atribuye significados diferentes al término «bueno» y porque intervienen elementos variados y muy diversos. Sin embargo, a partir del acuerdo que parece haber en que todo lo que constituye al "buen" maestro forma parte del «ethos docente», en el artículo se desarrolla lo que configura el rol de maestro desde la vertiente ética, elemento componente imprescindible, vinculándolo con los conceptos de identidad profesional y liderazgo moral, en los que las actitudes en las relaciones juegan un papel esencial. El artículo, desde la vertiente teórica, corrobora y complementa los resultados de los datos de una investigación con una muestra de maestros en ejercicio, considerados "buenos" por sus compañeros y, a partir de la cual emergieron cuáles eran las características de lo que consideraban un «buen maestro».

Palabras clave: Ethos docente; identidad profesional; liderazgo moral; formación del profesorado; educación moral; maestro; ética profesional.

\title{
Le côté éthique du "bon» enseignant. Ethos d'enseignant, identité professionnelle et leadership moral : quelques données
}

Résumé: Il est relativement complexe de répondre à la question de savoir comment devenir un bon enseignant car le terme «bon» peut revêtir différents sens et faire intervenir des éléments variés et très divers. Cependant, en partant du principe que tout ce qui constitue le «bon» enseignant fait partie de l' «ethos d'enseignant», le présent article étaye une vision du rôle de l'enseignant du point de vue éthique -élément constitutif indispensable- en l'associant aux concepts d'identité professionnelle et de leadership moral, dans lesquels les comportements relationnels jouent un rôle essentiel. Du point de vue théorique, l'article corrobore et complète les résultats des données obtenues d'une recherche avec ceux d'un échantillon d'enseignants en exercice, considérés par leurs collègues comme étant de «bons» enseignants, et qui a permis de dégager les caractéristiques de ce qu'ils considéraient comme un «bon enseignant».

Mots clés: Ethos d'enseignant, identité professionnelle, leadership moral, formation d'enseignants, éducation morale, enseignant, éthique professionnelle.

\section{The ethical face of the "good" teacher: findings on the subject of teaching ethos, professional identity and moral leadership}

\begin{abstract}
The question of how good teachers are made is particularly complex because "good" may be defined in many different ways or in terms of very diverse variables. However, it seems clear that the defining features of a good teacher are also key elements in a community's "teaching ethos". Based on this assumption, the article analyses the role of teachers from an ethical point of view, giving special attention to the links between teaching role and professional identity and moral leadership, which in turn are heavily influenced by attitudes and interpersonal relationships. This theoretical analysis substantiates and complements the emerging results of an empirical study with a sample of in-service teachers identified as "good teachers" by their colleagues, thus providing an operational definition of good teaching.
\end{abstract}

Keywords: Teaching ethos, professional identity, moral leadership, teacher training, moral education, teachers, professional ethics. 